\title{
Bioprinting: Prospects, considerations and challenges for application in South African clinical environments
}

\author{
S Fanucci, BSc (Hons); M W Barwick, BSc (Hons); E Prinsloo, PhD, PGDHE \\ Biotechnology Innovation Centre, Rhodes University, Grahamstown, South Africa
}

Corresponding author: E Prinsloo (e.prinsloo@ru.ac.za)

Bioprinting advances have revolutionised drug discovery and are set to disrupt biomedical research and medical application through the development of reproducible, fine-tuned functional 3D tissues and, eventually, whole organs. This intersectional bottom-up approach of additive manufacturing requires collaboration between tissue engineers, materials chemists, software and electrical engineers and medical practitioners for the software, hardware and wetware required by this disruptive technology. This review provides a current overview of the state of the art of bioprinting and the biomaterials/bioinks required, as well as the challenges and prospects for medical application in South Africa.

S Afr Med J 2019;109(8 Suppl 1):S35-S40. https://doi.org/10.7196/SAMJ.2019.v109i8b.13838

Additive manufacturing (AM), a computer-controlled bottom-up building approach, has recently found its place within the medical sphere with an increasing portfolio of healthcare applications. There are four main foci of this technology in medicine: (i) anatomical models; (ii) surgical equipment; (iii) organic and non-organic implants; and (iv) prostheses. ${ }^{[1]}$

Three-dimensional (3D) printing is an interdisciplinary AM technology that has rapidly advancing applications in medicine. ${ }^{[2]}$ Although prototyping, design and development remain the top uses of AM ( 64\%), applications in the medical field are seeing a rapid increase. In 2010, 3\% of hospitals in the USA made use of centralised 3D printing facilities, whereas in 2016, this increased to $99 \%$ of US hospitals, where applications ranged from custom prosthetics to 3D printed organ models from CT scans for patient education and surgical guides. ${ }^{[3,4]}$ Official statistics regarding $3 \mathrm{D}$ printer usage in South African hospitals are largely unknown.

As part of regenerative medicine, 3D printing applications focus largely on the engineering of functional human tissue termed bioprinting that makes use of specially designed bioinks (hydrogelbased biomaterials) in the fabrication of tissue constructs by patterning using modified 3D printing technology. It reduces the gap between ex vivo cell cultures and in vivo cellular tissue models, and there has been a significant increase in research and development for biomedical application. ${ }^{[5]} 3 \mathrm{D}$ printing has been used in healthcare for manufacturing of hearing aids, prosthetics and dental apparatuses. In the medical field, AM has been confined to the production of static structures, such as patient-specific craniofacial implants, hip and mandibular prostheses and the manufacturing of scaffolds for tissue engineering. While it is far from being a commonplace clinical application, the field has seen rapid growth in bioink/biomaterial development, hardware and software advancement, and preclinical testing for eventual clinical translation.

Bioprinting meets the demand of highly personalised clinical treatments by using magnetic resonance imaging (MRI) or computed tomography (CT) scans and computer-aided design (CAD) software to design patient-specific constructs (both organic and non-organic) to address concerns of rejection currently faced in organ transplant therapies by using the patient's own cells. One of the most important and immediately applicable technologies is the ability to create in vitro, patient-specific disease models for tailored drug discovery in personalised medicine. ${ }^{[6]}$ Aside from the ethical and regulatory issues faced with implementing bioprinted constructs towards clinical translation, consideration must be given to the difficulties in developing accurate and adequate biomaterials, manufacturing strategies and vascularisation. ${ }^{[7]}$ Previously, the choice in biopolymers used for conventional 3D tissue engineering has typically been based on availability and previous experience with these materials; however, the focus has recently shifted towards more complex bioink formulations to more accurately resemble the responsiveness of native extracellular matrices. ${ }^{[8]}$ Furthermore, these novel bioinks are not always compatible with the growing number of commercially available $3 \mathrm{D}$ bioprinters and typically lack the structural integrity needed for optimal bioprinting. ${ }^{[9]}$ Engineering vascular networks within tissue constructs is perhaps the greatest challenge faced by researchers, ${ }^{[10]}$ as tissues of the simplest structures will not survive without the necessary network for waste disposal and nutrient delivery. ${ }^{[7]}$

Along with the development of more efficient bioprinting processes, there are simultaneously, rapidly growing alternative technologies/research areas that aim to target organ shortages and patient-specific therapies within the field of regenerative medicine. Organ decellularisation and recellularisation is of particular interest as a newly emerging tissue engineering strategy. ${ }^{[11]}$ Organ decellularisation is a top-down approach to tissue engineering and focuses on the use of chemically and enzymatically decellularised extracellular matrices (ECMs) to allow for cell seeding. ${ }^{[12]}$ This strategy has been studied with regards to volumetric muscle loss, ${ }^{[12]}$ intervertebral disk degeneration, ${ }^{[13]}$ vascular grafts, ${ }^{[14,15]}$ constructing miniature humanised hearts for improved drug discovery systems and understanding cardiac biology, ${ }^{[1,17]}$ as well as diabetes, through pancreatic organ engineering. ${ }^{[18,19]}$ Issues faced with transplanting of bioengineered organs, such as vascular perfusion, recellularisation, engraftment and, importantly, animal survival, have recently been tackled with great success by Nichols et al. ${ }^{[20]}$ in a recellularised lung transplantation in a preclinical porcine model. Organ complexity with respect to level of organisation and cellular heterogeneity is a 
major stumbling block in this technology, and the same can be said about it being a major hurdle for the future of bioprinted organs.

This review aims to outline AM for medical application, the state of the art of $3 \mathrm{D}$ bioprinting with respect to available and developing hardware and related techniques, biomaterial research and development and application in personalised drug discovery and regenerative medicine. A proposal of the future of this technology in clinical application within South Africa (SA) is also discussed.

\section{Non-organic additive manufacturing in medicine}

The rapid prototyping nature of $3 \mathrm{D}$ printing speaks to the needs of the demanding clinical environment. To find its place in biomedical applications, the technology must meet the demands of high complexity, improved accessibility to the technology (for both patients and clinicians), ease of customisation, patient-specific necessities, small production quantities and, most importantly, easy public access. ${ }^{[21]}$ The small production quantity speaks to the bespoke manufacturing of highly complex objects nature of 3D printing. As of 2018, the main types of AM techniques used in the biomedical field include: powder-bed fusion; inkjet printing and contour crafting; stereolithography; and direct energy deposition (Table 1). ${ }^{[21]} \mathrm{A}$ hallmark of AM is that it allows engineers to rapidly manufacture and iterate designs, which ultimately reduces time to market. This is important in the medical field as the success of any newly manufactured medical device relies heavily on the feedback from physicians and patients, and AM can then allow for a more rapid speed at which the design improvements may be implemented. This fast feedback loop accelerates design development and will encourage rapid diagnostics and treatment. The biomedical market is one of the greatest drivers for AM advancement - it represents $11 \%$ of the total AM market share to date. ${ }^{[21]} \mathrm{AM}$ is proving to be vital in many patient-specific therapies that rely heavily on the ability to customise treatments to individual patients. Hearing aids, ${ }^{[22]}$ drug delivery methods, ${ }^{[23,24]}$ dental, ${ }^{[25]}$ orthopaedic ${ }^{[26]}$ and paediatric implants ${ }^{[27]}$ are a few of the therapies that have been revolutionised by the development of AM technologies. Furthermore, in the hope of reducing complication rates, researchers have found $3 \mathrm{D}$ printing to be invaluable in providing medical students with more realistic models for better preparation before performing complicated surgeries on real patients. ${ }^{[28]}$

These applications further highlight $3 \mathrm{D}$ printing as an attractive endeavour within the clinical field in terms of its highly personalised patient-specific designs, on-demand fabrication of complex structures and high precision. The National Institutes of Health (NIH) 3D Print Exchange (https:// https://3dprint.nih.gov) is an online repository of biomedical 3D printing files, modelling tutorials and educational material. ${ }^{[29]}$ With AM being medicine's next frontier, making the

\begin{tabular}{|c|c|c|}
\hline Application & Technology & Percentage (\%) \\
\hline \multirow[t]{6}{*}{ Anatomical models } & Powder-bed fusion & $24^{[59]}$ \\
\hline & Material extrusion & $32^{[60]}$ \\
\hline & Material jetting & $12^{[61]}$ \\
\hline & Vat photopolymerisation & $15^{[62]}$ \\
\hline & Binder jetting & $8^{[63]}$ \\
\hline & Bioprinters & $1^{[64]}$ \\
\hline \multirow[t]{5}{*}{ Prosthetics and/or orthotics } & Powder-bed fusion & $23^{[65]}$ \\
\hline & Material extrusion & $38^{[66]}$ \\
\hline & Material jetting & $15^{[67]}$ \\
\hline & Vat photopolymerisation & $8^{[68]}$ \\
\hline & Binder jetting & $9^{[67]}$ \\
\hline \multirow[t]{5}{*}{ Dentistry } & Powder-bed fusion & $16^{[69]}$ \\
\hline & Material extrusion & $16^{[70]}$ \\
\hline & Material jetting & $19^{[69]}$ \\
\hline & Vat photopolymerisation & $26^{[71]}$ \\
\hline & Binder jetting & $3^{[72]}$ \\
\hline \multirow[t]{6}{*}{ Non-resorbable patient-matched implants } & Powder-bed fusion & $45^{[73]}$ \\
\hline & Material extrusion & $10^{[74]}$ \\
\hline & Material jetting & $5^{[67]}$ \\
\hline & Vat photopolymerisation & $10^{[75]}$ \\
\hline & Binder jetting & $5^{[76]}$ \\
\hline & Direct energy deposition & $10^{[77]}$ \\
\hline \multirow[t]{5}{*}{ Resorbable patient-matched implants (including scaffolds) } & Powder-bed fusion & $23^{[3]}$ \\
\hline & Material extrusion & $15^{[78]}$ \\
\hline & Material jetting & $8^{[79]}$ \\
\hline & Vat photopolymerisation & $15^{[80]}$ \\
\hline & Binder jetting & $15^{[81]}$ \\
\hline
\end{tabular}


technologies publicly available is an essential step toward successful application. Despite its noteworthy progress in the medical field, applying AM technologies to existing therapies has limitations. Although non-organic implants have favourable mechanical strength and frictionresistance, the high strength and elastic modulus do not match that of native bone tissue and therefore can cause prosthetic loosening due to a stress-shielding effect. ${ }^{[30]}$ Furthermore, the preferred materials used for non-organic implants include gold, titanium and stainless steel, which are incompatible with magnetic resonance imaging (MRI). This limits the possibility of postoperative MRI examinations. ${ }^{[30]}$ Hypersensitivity reactions can also be triggered with longterm presence of non-organic materials within the human body. ${ }^{[30]}$ While nonorganic AM technologies are leading the charge for AM to the clinic, there remains a growing demand for a more regenerative approach. Bioprinting, through the use of stem cells, biomaterials and controlled patterning, provides a viable option within tissue engineering.

\section{Bioprinting: A highly specialised manufacturing approach} Biofabrication has shown to be of great importance and potential in regenerative medicine by allowing the generation of constructs that closely resemble the complexity of tissues and organs. ${ }^{[31]}$ Biofabrication can be defined as the exploitation of self-arrangement and selfassembly of biological systems to form biologically functional and structurally organised constructs; ${ }^{[31]}$ positional control through the bioprinting process further facilitates this. Bioprinting and bioassembly fall under and constitute a pedestal of biofabrication. ${ }^{[31]}$

A rapidly advancing technology such as bioprinting has many different approaches. However, all follow the same pre-processing (imaging, design approach, material selection, cell selection), processing (bioprinting inkjet, microextrusion, laserassisted, direct light processing) and post-processing (application, maturation, implantation, in vitro testing) workflow. ${ }^{[7,32,33]}$ The three pillars of successful bioprinting include hardware, software and wetware considerations, as outlined in Fig. 1. Liu et al. ${ }^{[34]}$ provide an in-depth review of the different types of bioprinter. There are five main principles for bioprinting: stereolithography, extrusion-based, laser- assisted, inkjet-based and nano-printing. ${ }^{[35]}$ Extrusion-based bioprinting has been largely focused on for the manufacture of 3D tissue constructs, owing to its many advantages compared with other methods, including but not limited to the following: high cell viability; ${ }^{[7]}$ flexible geometric shapes ${ }^{[36]}$ ability to incorporate multiple biomaterials and cell types; ${ }^{[37]}$ homogenous and heterogeneous structures can be created ${ }^{[33,36]}$ easily updated software and hardware; and the ability to include multiple bioinks/biomaterials in order to account for the high level of complexity within tissues and organs. Disadvantages such as the need for low viscosity of bioinks, lack of precision of droplets, distortion of cell structure, long printing times, high cost and use of intense UV light make inkjet, microextrusion, laser-assisted and direct light processing bioprinting less favourable than extrusion based bioprinting for regenerative cell therapies. ${ }^{[7,55,56]}$ Although extrusion-based bioprinting has been the most widely accepted method for tissue engineering, developments are still being made such as the multi-head deposition system which allows for the manufacturing of increasingly complex tissues. ${ }^{[38]}$ In situ bioprinting has also been cited as a promising approach to regenerative medicine in terms of facilitating graft or implant customisation and also, providing the building blocks to drive translational research. ${ }^{[38]}$ Bioprinting has the potential of revolutionising personalised medicine and drug discovery. ${ }^{[24]}$ It has been predicted to cause a substantial paradigm shift in drug

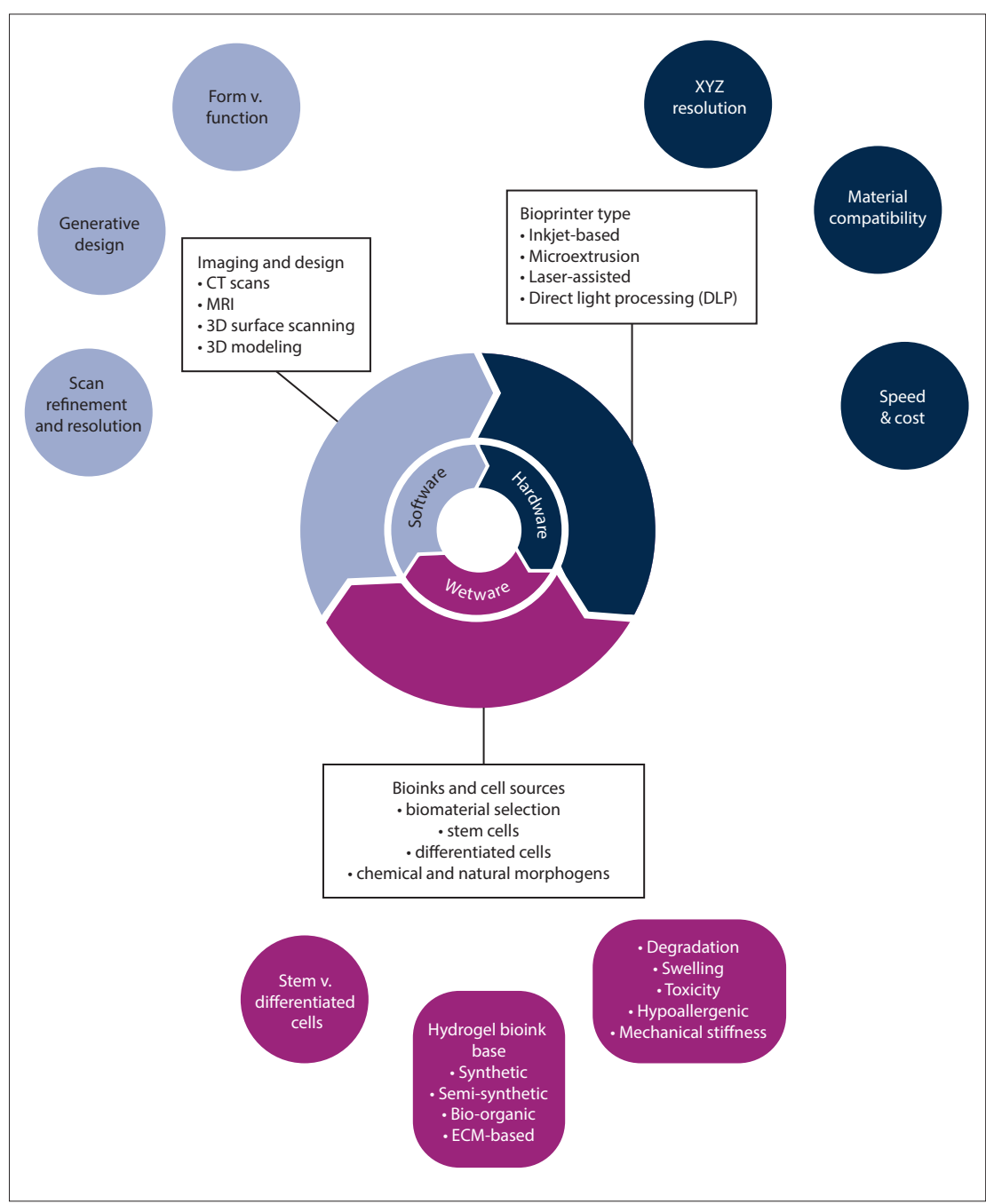

Fig. 1. Considerations for rapid prototyping in bioprinting. The interlinked process model describes the three pillars required for successful bioprinting, i.e. software, hardware and wetware development. Here, wetware is used as an all-encompassing term to describe bioprinted materials and tissues. Factors that influence imaging and design (software), types of bioprinter (hardware) and bioinks and cell sources (wetware) are shown in smaller circles outside the interlinked circles. (CT = computed tomography; $M R I=$ magnetic resonance imaging; $E C M=$ extracellular matrix.) 
design, formulation and production by providing flexibility and autonomy to existing treatment processes.

Control of the printing process is highly reliant on positioning of the $3 \mathrm{D}$ printhead, which is itself dependent on the input data. The Radiological Society of North America (RSNA) 3D printing Special Interest Group (SIG) recently proposed guidelines with respect to the use of imaging data for application in medical 3D printing. ${ }^{[39]}$ These include guiding principles on image resolution and processing, through to the eventual maintenance of image fidelity in 3D printing and post-processing of the printed construct. While these guidelines are highly applicable to the process of bioprinting, there should be consideration for the inclusion of generative design. Generative design is a computer-controlled human-guided design process that utilises a biomimicry approach to building stable, efficient structures that could assist greatly in bioprinting, considering the micron scales of biological detail. ${ }^{[40]}$

The levels of scale and organisation in biological tissues and organs cannot be ignored and is an important factor in bioprinter development and selection, as the XYZ resolution in current printing processes is controlled by both the printer as well as the bioink.

\section{Biomaterials and bioinks}

There are two main types of cells that can be used for bioprinting stem cells and differentiated cells. Stem cells are the favoured type of cell choice as they have properties of self-renewal and potency, allowing for an unlimited cell source for bioprinting. In addition to this, stem cells have low immunogenicity properties, favouring their use in bioprinting for regenerative medicine. Differentiated cells lack potency and have a finite life span as well as increased immunogenicity effects, which disadvantages them for use in bioprinting for regenerative medicine. ${ }^{[41,42]}$

Biomimicry, in which function follows form, is the most widely used approach to bioprinting; this is a strong consideration when approaching the development of wetware (Fig. 1). ${ }^{[7]}$ In order to achieve a construct that closely mimics that of native tissue, specifically designed and formulated bioinks are used. There are two main types of bioink materials currently used in 3D bioprinting. ${ }^{[43]}$ The first is a cell scaffold-based method in which the bioinks consist of biomaterials combined with living cells, used to print 3D tissue constructs. The second method makes use of cells printed directly in a manner in which it resembles normal embryonic growth and patterning. ${ }^{[43]}$ These neotissues form functional tissue structures over time. ${ }^{[43]}$ Biomaterials incorporated in the bioink formulations are included to promote in vivo revascularisation in the host tissue, safely degrade at a similar rate of tissue formation and prevent inflammatory responses which could cause rejection of the new tissue. ${ }^{[44,45]}$

In cell scaffold-based bioprinting, scaffolds are used in order to minimise and control the complexities found within native tissues. ${ }^{[8,46]}$ An optimally designed scaffold will closely mimic the native structural and mechanical properties of a target tissue. ${ }^{[7]}$ A poorly designed scaffold, on the other hand, will result in ineffective cell seeding and reduced cell viability, which will in turn result in poorly engineered tissue models. ${ }^{[47]}$

The term 'scaffold' refers to an artificially designed 3D structure which allows for the growth and proliferation of seeded cells such that the combination of cells and scaffold produce a viable tissue model..$^{[2]}$ Scaffolds are essentially artificially engineered extracellular matrices (ECMs). The design and optimisation of artificial scaffolds for tissue engineering is an attractive avenue in the advancement of bioprinting as the success of the printed tissue model relies heavily on the microenvironment in which the cells are grown. ${ }^{[8]}$ Furthermore, the architectural design of scaffolds greatly influences mechanical properties and cell behaviour. ${ }^{[48]}$ Scaffolds and other printed constructs are engineered from commonly used medical images using $\mathrm{CAD}$, making bioprinting a highly custom- and patient-specific technology. ${ }^{[2,7]}$ Scaffolds need to provide appropriate attachment factors, whether biological or structural, in order to support cells during deposition, which is a process characterised by substantial mechanical and thermal changes. ${ }^{[7]}$

The modification of scaffolds in terms of their structural design, surface properties, addition of various bioactive molecules or nanoparticles for the enhancement of attachment, proliferation and differentiation of specific target stem cells is referred to as 'smart scaffold' design. Designing appropriate scaffolds and bioinks remains the core challenge in the advancement of $3 \mathrm{D}$ tissue engineering and has frequently been cited as the most common inhibitor of bioprinting technology growth. ${ }^{[32]}$

Hydrogels are water-swollen polymers used as scaffold materials in $3 \mathrm{D}$ tissue engineering, as they are tunable, affordable, biocompatible, biodegradable, safe and have desirable mechanical properties similar to natural ECMs. ${ }^{[46]}$ Hydrogels have either synthetic (polyethylene oxide (POE), poly(vinyl alcohol), poly(acrylic acid)) or natural (alginate, collagen, hyaluronic acid) polymer chains. ${ }^{[49]}$ To address the issues related to lack of vascularisation in $3 \mathrm{D}$-printed tissue constructs, there has been an increasing focus on the development of more complex and responsive scaffold materials. Earlier studies were focused on simpler alginate, collagen and agarose-based bioinks, while more recent studies have developed application-specific bioink formulations. ${ }^{[50]}$ Supramolecular polymers have been investigated as potential alternatives to hydrogels as the primary scaffold material used in tissue engineering and AM. ${ }^{[51]}$ Four-dimensional (4D) printed scaffolds have also been a focus of recent studies, tying into the 'smart scaffold' concept, where 3D shape memory polymers are exploited to deliver time-controlled stimulus on encapsulated cells. ${ }^{[9]}$ It may be argued that bioprinting in itself may be classed as $4 \mathrm{D}$ printing (the fourth dimension being time), as cells and the printed construct as a whole change over time depending on the environment. This may be key to driving neovascularisation of printed constructs through the defined patterning of seed cells (endothelial) and homing beacons (e.g. vascular endothelial growth factor) to stimulate the vascularisation process.

Importantly, the success of a novel bioink as scaffold material in an engineered tissue construct relies heavily on the ability to $3 \mathrm{D}$ bioprint the newly designed bioink. The advancement of 3D printer technology is as imperative as the development of novel scaffolds in successful tissue engineering. Older $3 \mathrm{D}$ printers are not designed to print complex bioinks and have provided the basis for further $3 \mathrm{D}$ printing development.

\section{The South African bioprinting context}

The South African Department of Science and Technology (DST) officially launched its Additive Manufacturing Strategy in 2015 outlining a road map for adoption of AM as the cornerstone of SA's contribution to the Fourth Industrial Revolution. ${ }^{[52]}$ Approximately ZAR358 million has been invested into the advancement of 3D printing technologies since 2014. AM provides a unique opportunity to offer more localised and distributed research systems, a more sustainable and open-source economic model, and allows for an increase in investments and decrease in maintenance. While the strategy is largely targeted at the traditional manufacturing sector, the adoption of the technology in SA and the trickle-down effect 
Table 2. Bioprinting and non-organic AM technology for drug discovery and clinical application in South Africa

\begin{tabular}{lll}
\hline Institution & AM technology & Application \\
\hline North-West University & Cellink BioX & Drug discovery* \\
University of the Witwatersrand & EnvisionTec GmbH 3D Bioplotter (4th generation) & Drug discovery ${ }^{*}$ and drug delivery \\
Rhodes University & $\begin{array}{l}\text { Proprietary system under development (2nd generation } \\
\text { prototype) }\end{array}$ & Drug discovery \\
Central University of Technology & Multiple non-organic commercial systems & Clinical implants (titanium) \\
*Development of 3D tissue models. & &
\end{tabular}

on the medical and healthcare sector cannot be underestimated. The contribution to biomedical research and clinical applications in SA is yet to be determined. Table 2 presents current efforts at various institutions in SA with respect to biomedical AM and bioprinting. While the Central University of Technology Centre for Rapid Prototyping and Manufacturing has made a significant contribution to the development of medical AM applications through the development of titanium implants, ${ }^{[53-56]}$ most of the current efforts around organic bioprinting with bioinks are centred on the development of reproducible preclinical human drug discovery models (see Sithole et al. ${ }^{[48]}$ ). The clinical importance of these systems cannot be ignored with respect to the establishment of a personalised medicine therapeutic pipeline. Stellenbosch University has recently launched a 3D printing laboratory in partnership with the Division of Orthopaedics at Tygerberg Hospital, which is focused on the delivery of patient-specific models for surgical planning and represents a further leap in establishing the promise of this technology within the SA clinical environment. These projects feed into the South African Bioeconomy Strategy, with the health sector being identified as one of three key economic sectors most in need of implementation of the aforementioned strategy. A strategic focus placed on bioprinting and medical 3D printing will therefore certainly aid SA to achieve the strategic goals within the health sector. Furthermore, projects focused on bioprinting aim to provide key research into the engineering of tissue, which will address the disease burden prevalent in SA and will therefore contribute substantially to the advancement of the biopharmaceutical industry in SA. ${ }^{[57]}$ Research into the advancement of bioprinting and AM can in turn aid in transforming the SA economy into a knowledge-based economy, which is the second initiative of the Bioeconomy Strategy.

The African Tissue Engineering and Regenerative Medicine International Society (ATERMIS) was officially launched in 2017 at the 2nd International Conference on Tissue Engineering and Regenerative Medicine as the African chapter of the Tissue Engineering and Regenerative Medicine International Society (TERMIS) to build and strengthen tissue engineering research and translation thereof within Africa. ${ }^{[58]}$ This Society provides a viable platform to propose bioprinting workshops and workgroups/networks of all researchers and practitioners currently working in or with an interest in the field. Workshops would be of benefit to bring together clinicians and researchers to build translational application of laboratory investigations. Arguably the largest grouping of scientists working within this field in Africa is in SA, owing to excellent research facilities and $\mathrm{n}$ environment conducive to to foster further development. Within the context of the DST BioEconomy and the AM strategies, available relevant expertise needs to be leveraged.

\section{Conclusions}

AM has the potential to produce viable and functional structures for the advancement of personalised medical care. ${ }^{[3]}$ Three-dimensional printing meets various demands of individualised medical treatments and has numerous advantages. However, it is a relatively new technology in the clinical environment, and current challenges include: designing appropriate bioinks; manufacturing more efficient bioprinters; addressing the lack of vasculature present in printed constructs; and maintaining long-term survival of the printed tissue constructs. ${ }^{[--8]}$ To date this type of AM has not been extensively applied in the clinical environment but still shows great potential in providing alternative and reliable personalised therapies. ${ }^{[3]}$ While whole-organ printing is not yet a reality, further dedicated research and time will help current AM technologies evolve into revolutionary treatment alternatives.

Acknowledgements. The authors would like to acknowledge the funders, National Research Foundation (SA), South African Medical Research Council (SAMRC) and Rhodes University.

Author contributions. SF and EP drafted the tables, figures and manuscript. MWB contributed to the editing of the manuscript.

Funding. This work was funded as part of the NRF (South Africa) Thuthuka and South African Medical Research Council (SAMRC) SelfInitiated Research Grant awarded to EP. We acknowledge NRF and Rhodes University for bursary support for SF and MWB.

Conflicts of interest. None.

1. Dodziuk H. Applications of 3D printing in healthcare. Kardiochirurgia i torakochirurgi 2016;13(3):283-293. https://doi.org/10.5114/kitp.2016.62625

2. Ji S, Guvendiren M. Recent advances in Bioink design for 3D Bioprinting of Tissues and Organs. Fron Bioeng Biotechnol. 2017;5:23. https://doi.org/10.3389/fbioe.2017.00023

3. Morrison RJ, Hollister SJ, Niedner MF, et al. Mitigation of tracheobronchomalacia with 3D-printed personalized medical devices in pediatric patients. 2015;7(285):285ra64-285ra64. https://doi. org/10.1126/scitranslmed.3010825

4. Smart Manufacturing Experience (SME). Medical Additive Manufacturing/3D Printing Annual Report 2018. https://wwwsme.org/globalassets/sme.org/media/white-papers-and-reports/2018-smemedical-am3dp-annual-report.pdf (accessed 14 February 2019).

5. Chua CK, Yeong WY, An J. Special Issue: 3D Printing for Biomedical Engineering. Materials Chua CK, Yeong WY, An J. Special Issue: 3D Priting
2017;10(3):243. https://doi.org/10.3390/ma10030243

6. Awad A, Trenfield SJ, Goyanes A, Gaisford S, Basit AW. Reshaping drug development using 3D printing. Drug Discov Today 2018;23(8):1547-1555. https://doi.org/10.1016/j.drudis.2018.05.025

. Bishop ES, Mostafa S, Pakvasa M, et al. 3-D bioprinting technologies in tissue engineering and Bishop ES, Mostafa S, Pakvasa M, et al. 3-D bioprinting technologies in tissue engineering and
regenerative medicine: Current and future trends. Genes Dis 2017;4(4):185-195. https://doi regenerative medicine: Current
org/10.1016/.j.gendis.2017.10.002

org/10.1016/j.gendis.2017.10.002 Aljohani W, Ullah MW, Zhang X, Yang G. Bioprinting and its applications in tissue engineering
and regenerative medicine. Int J Biol Macromol 2018;107:261-275. https://doi.org/10.1016/j. ijbiomac.2017.08.171

9. Hendrikson WJ, Rouwkema J, Clementi F, van Blitterswijk CA, Farè S, Moroni L. Towards 4D printed scaffolds for tissue engineering: Exploiting 3D shape memory polymers to deliver time-controlled stimulus on cultured cells. Biofabrication 2017;9(3):031001. https://doi.org/10.1088/1758-5090/aa8114

10. Ke D, Murphy S V. Current challenges of vascularization for bioprinted organs towards clinical translations. Tissue Eng Part B Rev 2018;25(1):1-13. https://doi.org/10.1089/ten.teb.2018.0132

11. Garreta E, Oria R, Tarantino C, et al. Tissue engineering by decellularization and 3D bioprinting. 2017;20(4):166-178. https://doi.org/10.1016/j.mattod.2016.12.005

12. Urciuolo A, Coppi P De. Decellularized tissue for muscle regeneration. Int J Mol Sci 2018;19(8)2392. https://doi.org/10.3390/ijms19082392

13. Hensley A, Rames J, Casler V, et al. Decellularization and characterization of a whole intervertebral disk xenograft scaffold. J Biomed Mater Res Part A 2018;106(9):2412-2423. https://doi.org/10.1002/ jbm.a.36434

14. Rambøl MH, Hisdal J, Sundhagen JO, Brinchmann JE, Rosales A. Recellularization of decellularized venous grafts using peripheral blood: A critical evaluation. EBioMedicine 2018;32:215-222. https://doi. venous grafts using peripheral blo

15. Kuna VK, Xu B, Sumitran-Holgersson S. Decellularization and recellularization methodology for human saphenous veins. J Vis Exp 2018;137:e57803. https://doi.org/10.3791/57803

16. Nguyen DT, O'Hara M, Graneli C, et al. Humanizing miniature hearts through 4-flow cannulation perfusion decellularization and recellularization. Sci Rep 2018;8(1):7458. https://doi.org/10.1038/ s41598-018-25883-x 
17. Ott HC, Matthiesen TS, Goh S, et al. Perfusion-decellularized matrix: Using nature's platform to engineer a bioartificial heart 2008;14(2):213-221. https://doi.org/10.1038/nm1684

18. Elebring E, Kuna VK, Kvarnström N, Sumitran-Holgersson S. Cold-perfusion decellularization of whole-organ porcine pancreas supports human fetal pancreatic cell attachment and expression of endocrine and exocrine markers. J Tissue Eng 2017:30(8):204173 https://doi. expression of endocrine and

19. Sackett SD, Tremmel DM, Ma F, et al. Extracellular matrix scaffold and hydrogel derived from decellularized and delipidized human pancreas. Sci Rep 2018;8(1):10452. https://doi.org/10.1038/ 41598-018-28857-1

20. Nichols JE, La Francesca S, Niles JA, et al. Production and transplantation of bioengineered lung into a large-animal model. Sci Transl Med 2018;10(452):eaao3926. https://doi.org/10.1126/scitranslmed. аaо3926

21. Ngo TD, Kashani A, Imbalzano G, Nguyen KTQ, Hui D. Additive manufacturing (3D printing): A review of materials, methods, applications and challenges. Compos Part B Eng 2018;143(15):172-196. https://doi.org/10.1016/j.compositesb.2018.02.012

22. Alifui-Segbaya F, George R, Alifui-Segbaya F, George R. Biocompatibility of 3D-printed methacrylate for hearing devices. Inventions 2018;3(3):52. https://doi.org/10.3390/inventions3030052

23. Warnken ZN, Smyth HDC, Davis DA, Weitman S, Kuhn JG, Williams RO. Personalized medicine in nasal delivery: The use of patient-specific administration parameters to improve nasal drug targetin using 3D-printed nasal replica casts. Mol Pharm 2018:15(4):1392-1402 https///doi org/10.1021/acs. molpharmaceut 7 b00702.

24. Liang K, Carmone S, Brambilla D, Leroux J. 3D printing of a wearable personalized oral delivery device: A first in-human study. Science Advances 2018;4(5):eaat2544. https://doi.org/10.1126/sciadv aat2544

25. Prasad S, Kader NA, Sujatha G, Raj T, Patil S. 3D printing in dentistry. J 3D Print Med 2018;2(3):89-91. https://doi.org/10.2217/3dp-2018-0012

26. Mukherjee P, Cheng K. 3D printing and virtual surgical planning in a difficult Bonebridge case. Virtual Phys Prototyp 2018:14(1):53-58. https://doi.org/10.1080/17452759.2018.1513797

27. Wickramasinghe S, Navarreto-Lugo M, Ju M, Samia ACS. Applications and challenges of using 3D printed implants for the treatment of birth defects. Birth Defects Res 2018;110(13):1065-1081. https:/ doi.org/10.1002/bdr2.1352

28. Society of Interventional Radiology. 3-D-printed models improve medical student training: Les expensive and more realistic 3-D models of blood vessels may offer alternative to the commercial standard. ScienceDaily 2018. https://www.sciencedaily.com/releases/2018/03/180320084352.htm (accessed 20 November 2018).

29. National Institutes of Health. NIH 3D Print Exchange. U.S. Department of Health and Human Services 2017. https://3dprint.nih.gov/ (accessed 2 December 2018)

30. Honigmann P, Sharma N, Okolo B, Popp U, Msallem B, Thieringer FM. Patient-specific surgical implants made of 3D Printed PEEK: Material, Technology, and Scope of Surgical Application. Biomed Res Int 2018;2018:1-8. https://doi.org/10.1155/2018/4520636

31. Moroni L, Boland T, Burdick JA, De Maria C, Derby B, Forgacs G, et al. Biofabrication: A guide to technology and terminology. Trends Biotechnol 2018;36(4):384-402. https://doi.org/10.1016/j. tibtech.2017.10.015

32. Murphy S V, Atala A. 3D bioprinting of tissues and organs. Nat Biotechnol 2014;32(8):773-785. https:// Murphy S V, Atala A. 3D b

33. Xia Z, Jin S, Ye K. Tissue and Organ 3D Bioprinting. SLAS Technol Transl Life Sci Innov 2018;23(4):301314. https://doi.org/10.1177/2472630318760515

34. Liu F, Liu C, Chen Q, Ao Q, Tian X, Fan J, et al. Progress in organ 3D bioprinting. Int J Bioprinting 2018;4(1):1-15. https://doi.org/10.18063/ijb.v4i1.128

35. Horch RE, Weigand A, Wajant $\mathrm{H}$, et al. Biofabrikation - neue Ansätze für den artifiziellen Gewebeersatz. Handchir Mikrochir Plast Chir 2018;50(02):93-100. https://doi.org/10.1055/s-0043-124674

6. You F, Eames BF, Chen X. Application of extrusion-based hydrogel bioprinting for cartilage tissue engineering. Int J Mol Sci 2017;18(7):1597. https://doi.org/10.3390/ijms18071597

7. Ding H, Chang RC. Printability study of bioprinted tubular structures using liquid hydrogel precursor in a support bath. Appl Sci 2018;8(3):403. https://doi.org/10.3390/app8030403

38. Miar S, Shafiee A, Guda T, Narayan R. Additive manufacturing for tissue engineering. 3D Print Biofabrication 2018:1-52. https://doi.org/10.1007/978-3-319-40498-1_2-1

39. Chepelev L, Wake N, Ryan J, et al. Radiological Society of North America (RSNA) 3D printing Special Interest Group (SIG): Guidelines for medical 3D printing and appropriateness for clinical scenarios. 3D Print Med 2018;4(1):11. https://doi.org/10.1186/s41205-018-0030-y

40. Gelber MK, Hurst G, Bhargava R. Freeform Assembly Planning. IEEE Transact Automation Sci Eng 2018:1-15. https://doi.org/10.1109/tase.2018.2878670

41. Ong CS, Yesantharao P, Huang CY, et al. 3D bioprinting using stem cells. Nature 2017;83(1-2):223-231. https://doi.org/10.1038/pr.2017.252

42. Dzobo $\mathrm{K}$, Thomford NE, Senthebane DA, et al. Advances in regenerative medicine and tissue engineering: Innovation and transformation of medicine 2018:2018:1-24. https://doi. org/10.1155/2018/2495848

43. Gopinathan J, Noh I. Recent trends in bioinks for 3D printing. Biomater Res 2018;22:11. https://doi. rg/10.118/50824-018-0122-1

44. Miller JS, Stevens KR, Yang MT, et al. Rapid casting of patterned vascular networks for perfusable engineered three-dimensional tissues. Nat Mater 2012;11(9):768-774. https://doi.org/10.1038 nmat 3357

5. O’Brien FJ. Biomaterials \& scaffolds for tissue engineering. Materials Today 2011;14(3):88-95. https:// doi.org/10.1016/s1369-7021(11)70058-x

6. Gungor-Ozkerim PS, Inci I, Zhang YS, Khademhosseini A, Dokmeci MR. Bioinks for 3D bioprinting. An overview. Biomater Sci 2018;6(5):915-946. https://doi.org/10.1039/c7bm00765e

47. Lozano R, Stevens L, Thompson BC, et al. 3D printing of layered brain-like structures using peptide modified gellan gum substrates. Biomaterials 2015;67:264-273. https://doi.org/10.1016/j. biomaterials.2015.07.02

48. Sithole MN, Kumar P, du Toit LC, Marimuthu T, Choonara YE, Pillay V. A 3D bioprinted in situ conjugated- $c 0$-fabricated scaffold for potential bone tissue engineering applications. J Biomed Mater Res Part A 2018;106(5):1311-1321. https://doi.org/10.1002/jbm.a.36333

49. Wang S, Lee JM, Yeong WY. Smart hydrogels for 3D bioprinting. Int J Bioprinting 2015;1(1):3-14. https://doi.org/10.18063/ijb.2015.01.005

50. Derakhshanfar S, Mbeleck R, Xu K, Zhang X, Zhong W, Xing M. 3D bioprinting for biomedical devices and tissue engineering: A review of recent trends and advances. Bioact Mater 2018;3(2):144-156. https://doi.org/10.1016/j.bioactmat.2017.11.008
51. Highley $\mathrm{CB}$, Rodell $\mathrm{CB}$, Burdick JA. Direct 3D printing of shear-thinning hydrogels into self-healing hydrogels. Adv Mater 2015;27(34):5075-5079. https://doi.org/10.1002/adma.201501234

52. Du Preez WB, De Beer DJ. Implementing the South African additive manufacturing technology roadmap - the role of an additive manufacturing centre of competence. S Afr J Ind Eng 2015;26(2):8592. https://doi.org/10.7166/26-2-1179

53. Du Preez W, Booysen G. Advances in Ti6Al4V additive manufacturing in South Africa. In: Venkatesh V, Pilchak AL, Alison JE, et al., eds. Proceedings of the 13th World Conference on Titanium. John Wiley \& Sons, Inc. 2016:1323-1329. https://doi.org/10.1002/9781119296126.ch22

54. Dzogbewu TC. Additive manufacturing of porous Ti-based alloys for biomedical applications - a review. J New Gener Sci 2017;15(1):278-294. http://hdl.handle.net/11462/1627

55. Du Plessis A, le Roux SG, Booysen G, Els J. Quality control of a laser additive manufactured medical implant by X-ray tomography. 3D Print Addit Manuf 2016;3(3):175-182. https://doi. org $/ 10.1089 / 3$ dp.2016.0012

56. Fernandes N, van den Heever J, Hoogendijk C, Botha S, Booysen G, Els J. Reconstruction of an extensive midfacial defect using additive manufacturing techniques. J Prosthodont 2016;25(7):589594. https://doi.org/10.1111/jopr.12487

57. Arbuthnot P, Maepa MB, Ely A, Pepper MS. The state of gene therapy research in Africa, its significance and implications for the future. Gene Therapy 2017;24(9):581-589. https://doi.org/10.1038/gt.2017.57

58. Dzobo K, Senthebane DA, Pillay M, Ssemakalu C. The future of tissue engineering and Regenerative Medicine in Africa. Tissue Engineering Part A 2017;23:1023-1025. https://doi.org/10.1089/ten. 2017.0375

59. Fasel JHD, Malis DD, Wiederer C, Hagenbuch N. 3D printing of anatomical models for surgeons: An investigation on repeatability. Int J Interact Des Manuf 2018;12(2):621-627. https://doi.org/10.1007/ 12008-018-0478-4

60. Smith ML, Jones JFX. Dual-Extrusion 3D Printing of Anatomical Models for Education Construction of Airway Models. Wiley 2017;11(1):65-72. https://doi.org/10.1002/ase.1730

61. Cloonan AJ, Shahmirzadi D, Li RX, Doyle BJ, Konofagou EE, McGloughlin TM. 3D-printed tissuemimicking phantoms for medical imaging and computational validation applications. 3D Print Addit Manuf 2014;1(1):14-23. https://doi.org/10.1089/3dp.2013.0010

62. Schicho K, Figl M, Seemann R, et al. Accuracy of treatment planning based on stereolithography in computer-assisted surgery. Med Phys 2006;33(9):3408-3417. https://doi.org/10.1118/1.2242014

63. Lichtenberger JP, Tatum PS, Gada S, Wyn M, Ho VB, Liacouras P. Using 3D printing (additive manufacturing) to produce low-cost simulation models for medical training. Mil Med 2018;183(1):7377. https://doi.org/10.1093/milmed/usx142

64. Bücking TM, Hill ER, Robertson JL, Maneas E, Plumb AA, Nikitichev DI. From medical imaging data to 3D printed anatomical models. PLoS ONE 2017;12(5):e0178540. https://doi.org/10.1371/journal. pone.0178540

65. Pereira TF, Silva MAC, Oliveira MF, et al. Effect of process parameters on the properties of selective laser sintered poly(3-hydroxybutyrate) scaffolds for bone tissue engineering. Virtual Phys Prototyp 2012;7(4):275-285. https://doi.org/10.1080/17452759.2012.738551

66. Nayak C, Singh A, Chaudhary H, Tripathi A. A novel approach for customized prosthetic socket design. Biomed Eng Appl Basis Commun 2016;28(3):1650022. https://doi.org/10.4015/s1016237216500228

67. Shirazi SFS, Gharehkhani S, Mehrali M, et al. A review on powder-based additive manufacturing for tissue engineering: Selective laser sintering and inkjet 3D printing. Sci Technol Adv Mater 2015 Jun 20;16(3):033502. https://doi.org/10.1088/1468-6996/16/3/033502

68. Choi J-Y, Choi J-H, Kim N-K, et al. Analysis of errors in medical rapid prototyping models. Int J Oral Maxillofac Surg 2002 Feb;31(1):23-32. https://doi.org/10.1054/ijom.2000.0135

69. Fiorenza L, Yong R, Ranjitkar S, et al. Technical note: The use of 3D printing in dental anthropology collections. Am J Phys Anthropol 2018;167(2):400-6. https://doi.org/10.1002/ajpa.23640

70. Juneja M, Thakur N, Kumar D, Gupta A, Bajwa B, Jindal P. Accuracy in dental surgical guide fabrication using different 3-D printing techniques. Addit Manuf 2018 Aug 1;22:243-55. https://doi. org/10.1016/i.addma.2018.05.012

71. Bammani SS, Birajdar PR, Metan SS. Dental crown manufacturing using stereolithography method. Proc Int Conf Adv Ind Prod Eng 2012;7-10. https://doi.org/10.1016/02.AIPE.2012.2.

72. Mostafaei AA, Stevens EL, Ference JJ, Schmidt DE, Chmielus M. Binder jetting of a complexshaped metal partial denture framework. Addit Manuf 2018;21:63-68 https://doi.org/10.1016/j. addma.2018.02.01

73. Ackland DC, Robinson D, Redhead M, Lee PVS, Moskaljuk A, Dimitroulis G. A personalized 3D-printed prosthetic joint replacement for the human temporomandibular joint: From implant design to implantation. J Mech Behav Biomed Mater 2017;69:404-411. https://doi.org/10.1016/j. jmbbm.2017.01.048

74. Oskui SM, Diamante G, Liao C, Shi W, Gan J, Schlenk D, et al. Assessing and reducing the toxicity of 3D-printed parts 2016;3(1):1-6. https://doi.org/10.1021/acs.estlett.5b00249

75. Bloomquist CJ, Mecham MB, Mark D, et al. Controlling release from 3D printed medical devices using CLIP and drug-loaded liquid resins. J Control Release 2018;278:9-23. https://doi.org/10.1016/j. jconrel.2018.03.026

76. Suwanprateeb J, Sanngam R, Suwanpreuk W. Fabrication of bioactive hydroxyapatite/bis-GMA based composite via three dimensional printing. J Mater Sci Mater Med 2008 Jul 16;19(7):2637-2645. https:// doi.org/10.1007/s10856-007-3362-5

77. Nakano T, Ishimoto T. Powder-based additive manufacturing for development of tailor-made implants for orthopedic applications. KONA Powder Part J 2015;32(32):75-84. https://doi.org/10.14356/ kona. 2015015

78. Ahlfeld T, Doberenz F, Kilian D, , et al. Bioprinting of mineralized constructs utilizing multichannel plotting of a self-setting calcium phosphate cement and a cell-laden bioink. Biofabrication $2018 \mathrm{Jul}$ 27;10(4):045002. https://doi.org/10.1088/1758-5090/aad36d

79. Nikitichev DI, Barburas A, McPherson K, Mari J-M, West SJ, Desjardins AE. Construction of 3-dimensional printed ultrasound phantoms with wall-less vessels. J Ultrasound Med 2016;35(6):13339. https://doi.org/10.7863/ultra.15.06012

80. Martinez PR, Goyanes A, Basit AW, Gaisford S. Fabrication of drug-loaded hydrogels with stereolithographic 3D printing. Int J Pharm 2017;532(1):313-317. https://doi.org/10.1016/j. ipharm.2017.09.003

81. Khalyfa A, Vogt S, Weisser I, et al. Development of a new calcium phosphate powder-binder system for the 3D printing of patient specific implants. J Mater Sci Mater Med 2007 May 14;18(5):909-916. https:// doi or $/ 10$ 10.1007/s10856-006-0073-2

82. Awad A, Tren SJ, Gaisford S, Basit AW. 3D printed medicines: A new branch of digital healthcare 2018;548(1):586-596. https://doi.org/10.1016/j.ijpharm.2018.07.024 